www.nature.com/ja

\title{
Diphenyl etheric metabolites from Streptomyces sp. neau50
}

\author{
Dian-Liang Gong ${ }^{1}$, Xiang-Jing Wang ${ }^{1}$, Zhi-Dan Xiang ${ }^{1}$, Ji-Dong Wang ${ }^{2}$, Hui Zhang ${ }^{2}$, Chong-Xi Liu' ${ }^{1}$, Ji Zhang ${ }^{1}$ \\ and Wen-Sheng Xiang ${ }^{1}$
}

The Journal of Antibiotics (2011) 64, 465-467; doi:10.1038/ja.2011.25; published online 6 April 2011

Keywords: cytotoxic activity; diphenyl ether; Streptomyces sp. neau50; structure elucidation

Natural products are among the most important resources of the clinically used cancer chemotherapeutic agents. Many compounds with anticancer properties have been isolated from natural sources since actinomycin was discovered in 1940's. More than $60 \%$ of the currently known compounds with anti-neoplasic activity are natural products or their derivatives. ${ }^{1-6}$ As part of the search for new and biologically active secondary metabolites produced by actinomyces from unexplored and underexplored ecological niches, an endophytic actinomycete Streptomyces sp. neau50 was isolated from healthy root of soybean. Initial screening of the crude extract exhibited cytotoxicity against certain cancer cell lines and inhibitory activity against phytopathogenic fungi. Subsequent isolation resulted in borrelidin as the major active component. To further investigate minor amount of active constituents in this strain, the fermentation was scaled up, and detailed fractionation of the crude extract led to the isolation of a novel diphenyl ether compound, methyl 2-hydroxy-4-(2-hydroy-3methoxy-5-methylphenoxy)-6-methylbenzoate (1), together with a known one, methyl 2-hydroxy-4-(3-hydroxy-5-methylphenoxy)-6methylbenzoate (2). In this paper, we describe the isolation, structure elucidation and bioactivities of 1 and 2 .

The producing strain, Streptomyces sp. neau50, was isolated by moist incubation and desiccation method from healthy soybean root in Harbin, Heilongjiang province, China. ${ }^{7}$ The 16S rRNA was sequenced for taxonomic classification (GenBank Accession No: GQ 494994).

The strain was maintained in the medium containing $10 \mathrm{~g}$ glucose, $3 \mathrm{~g}$ maltose, 3 g yeast extract, $0.5 \mathrm{~g} \mathrm{~K}_{2} \mathrm{HPO}_{4} 3 \mathrm{H}_{2} \mathrm{O}, 0.5 \mathrm{~g} \mathrm{MgSO}_{4} 7 \mathrm{H}_{2} \mathrm{O}$, $0.5 \mathrm{~g} \mathrm{NaCl}_{1} 1 \mathrm{~g} \mathrm{KNO}_{3}$ and $20 \mathrm{~g}$ agar in $1.01 \mathrm{tap}$ water, $\mathrm{pH}$ 7.0. Slant culture was incubated for $6-7$ days at $28^{\circ} \mathrm{C}$. The seed medium consisted of $4 \mathrm{~g}$ glucose, $10 \mathrm{~g}$ maltodextrin, $4 \mathrm{~g}$ yeast extract, $2 \mathrm{~g}$ $\mathrm{CaCO}_{3}$ in 1.01 water, $\mathrm{pH}$ 7.2-7.4. All the media were sterilized at $121^{\circ} \mathrm{C}$ for $20 \mathrm{~min}$.
Fermentation was carried out in a 50-1 first seed fermentor (containing 301 seed culture) and a 500-1 second fermentor (containing 3001 producing medium), successively. The producing medium comprised $1 \%$ glucose, $4 \%$ soluble amylum, $0.5 \%$ yeast extract, $2.5 \%$ soybean powder, $0.5 \%$ peptone, $0.2 \% \mathrm{CaCO}_{3}, 0.8 \% \mathrm{MgSO}_{4}$ $7 \mathrm{H}_{2} \mathrm{O}, 0.6 \% \mathrm{FeSO}_{4} 7 \mathrm{H}_{2} \mathrm{O}, 0.2 \% \mathrm{ZnSO}_{4} 7 \mathrm{H}_{2} \mathrm{O}, 0.2 \% \mathrm{MnSO}_{4} \mathrm{H}_{2} \mathrm{O}$, $0.05 \% \mathrm{CoCl}_{2} 6 \mathrm{H}_{2} \mathrm{O}, 0.2 \% \mathrm{Na}_{2} \mathrm{MoO}_{4} 2 \mathrm{H}_{2} \mathrm{O}$, pH 7.0. The fermentation was performed at $28^{\circ} \mathrm{C}$ for 7 days stirred at $100 \mathrm{rmin}^{-1}$ with an aeration rate of $30 \mathrm{~m}^{3}$ of air per hour.

The final 3001 of fermentation broth was filtered to afford the mycelial cake. After it was washed with water, the mycelia was extracted twice with 1001 of EtOH for about $24 \mathrm{~h}$. The EtOH extract was diluted to about $30 \% \mathrm{EtOH}$ and subjected to a Diaion HP-20 resin column, which was eluted with 30, 40, 50, 60, 70 and $80 \% \mathrm{EtOH}$ (each concentration eluted 2 bed volumes). The eluents at 70 and $80 \%$ EtOH were pooled and concentrated in vacuo at $50^{\circ} \mathrm{C}$. Then part of the concentrated material $(32 \mathrm{~g})$ was chromatographed on a silica gel column, and successively eluted with a stepwise gradient of petroleum ether-acetone (100:0-50:50, v/v) to obtain five fractions (fractions I-V) based on the TLC profiles. Fraction III was chromatographed on another silica gel column and eluted with petroleum ether-acetone (90:10-70:30, v/v) to give three subfractions. Subfraction II was then subjected to a Sephadex LH-20 column (GE Healthcare, Glies, UK) and eluted with EtOH to obtain fractions A and B. Finally, fraction B was fractionated by semi-preparative HPLC with column Zorbax SBC18 $(5 \mu \mathrm{m}, 250 \times 9.4 \mathrm{~mm})$ on Agilent 1100 system (Agilent, Palo Alto, $\mathrm{CA}$, USA). It was eluted with $\mathrm{CH}_{3} \mathrm{OH}-\mathrm{H}_{2} \mathrm{O}(85: 15$, v/v) at $1.5 \mathrm{ml} \mathrm{min}^{-1}$. Two main compounds $1\left(t_{\mathrm{R}} 11.8 \mathrm{~min}, 8 \mathrm{mg}\right)$ and $2\left(t_{\mathrm{R}}\right.$ $12.7 \mathrm{~min}, 11 \mathrm{mg}$ ) (Figure 1) were isolated.

Compound 1 was obtained as colorless oil with UV (EtOH) $\lambda_{\max } \mathrm{nm}(\log \varepsilon): 211$ (4.29), 264 (3.92), 299 (3.52). The absorption peaks in the IR spectrum of 1 suggested the presence of hydroxyl

\footnotetext{
${ }^{1}$ Life Science \& Biotechnology Research Center, School of Life Science, Northeast Agricultural University, Harbin, PR China and ${ }^{2}$ Department of New Drug Screening, Zhejiang Hisun Pharmaceutical, Co., Ltd, Zhejiang, PR China

Correspondence: Professor W-S Xiang, Life Science \& Biotechnology Research Center, School of Life Science, Northeast Agricultural University, No. 59 Mucai Street, Xiangfang District, Harbin 150030, PR China.

E-mail: xiangwensheng@yahoo.com.cn

Received 14 October 2010; revised 3 March 2011; accepted 8 March 2011; published online 6 April 2011
} 


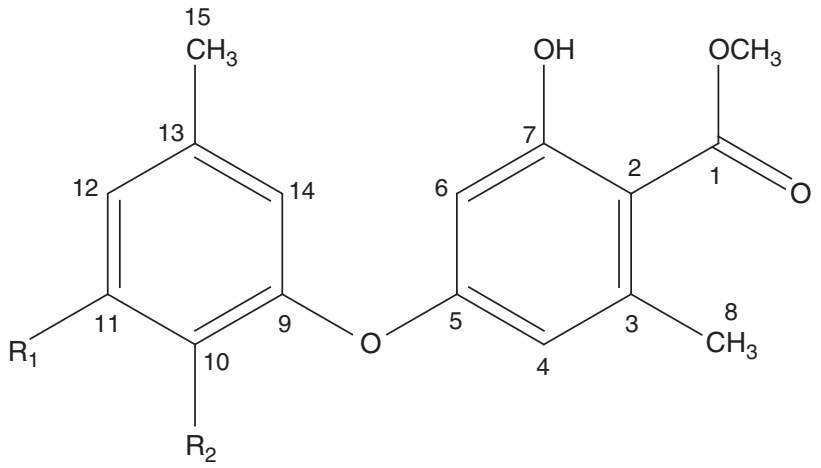

$1 \mathrm{R}_{1}=\mathrm{OCH}_{3}, \mathrm{R}_{2}=\mathrm{OH}$

$2 \mathrm{R}_{1}=\mathrm{OH}, \quad \mathrm{R}_{2}=\mathrm{H}$

Figure 1 Structures of compounds 1 and 2.

Table $1{ }^{1} \mathrm{H}$ and ${ }^{13} \mathrm{C}$ NMR data of compounds 1 and 2

\begin{tabular}{|c|c|c|c|c|}
\hline \multirow[b]{2}{*}{ No. } & \multicolumn{2}{|l|}{1} & \multicolumn{2}{|l|}{2} \\
\hline & $\delta_{H}$ (mult., $J$ in $H z$ ) & $\delta_{C}$ & $\delta_{H}$ (mult., $J$ in $\mathrm{Hz}$ ) & $\delta_{C}$ \\
\hline 1 & & $172.1 \mathrm{~s}^{\mathrm{a}}$ & & $172.0 \mathrm{~s}$ \\
\hline 2 & & $106.7 \mathrm{~s}$ & & $107.0 \mathrm{~s}$ \\
\hline 3 & & $143.6 \mathrm{~s}$ & & $143.6 \mathrm{~s}$ \\
\hline 4 & $6.42(1 \mathrm{H}, \mathrm{d}, 2.4)$ & $112.0 \mathrm{~d}$ & $6.37(1 \mathrm{H}, \mathrm{d}, 2.5)$ & $113.0 \mathrm{~d}$ \\
\hline 5 & & $162.5 \mathrm{~s}$ & & $162.3 \mathrm{~s}$ \\
\hline 6 & $6.27(1 \mathrm{H}, \mathrm{d}, 2.4)$ & $101.7 \mathrm{~d}$ & $6.34(1 \mathrm{H}, \mathrm{d}, 2.5)$ & $103.2 \mathrm{~d}$ \\
\hline 7 & & $165.2 \mathrm{~s}$ & & $165.0 \mathrm{~s}$ \\
\hline 8 & $2.50(3 \mathrm{H}, \mathrm{s})$ & $24.3 q$ & $2.50(3 \mathrm{H}, \mathrm{s})$ & $24.2 \mathrm{q}$ \\
\hline 9 & & $140.5 \mathrm{~s}$ & & $155.9 \mathrm{~s}$ \\
\hline 10 & & $135.7 \mathrm{~s}$ & $6.37(1 \mathrm{H}, \mathrm{br} \mathrm{s})$ & $105.0 \mathrm{~d}$ \\
\hline 11 & & $147.9 \mathrm{~s}$ & & $156.8 \mathrm{~s}$ \\
\hline 12 & $6.58(1 \mathrm{H}, \mathrm{br} \mathrm{s})$ & $109.0 \mathrm{~d}$ & $6.49(1 \mathrm{H}, \mathrm{br} \mathrm{s})$ & $112.6 \mathrm{~d}$ \\
\hline 13 & & $129.5 \mathrm{~s}$ & & $141.2 \mathrm{~s}$ \\
\hline 14 & $6.50(1 \mathrm{H}, \mathrm{br} \mathrm{s})$ & $115.1 \mathrm{~d}$ & $6.44(1 \mathrm{H}, \mathrm{br} \mathrm{s})$ & $113.4 \mathrm{~d}$ \\
\hline 15 & $2.28(3 \mathrm{H}, \mathrm{s})$ & $21.2 \mathrm{q}$ & $2.28(3 \mathrm{H}, \mathrm{s})$ & $21.4 \mathrm{q}$ \\
\hline $1-\mathrm{OCH}_{3}$ & $3.93(3 \mathrm{H}, \mathrm{s})$ & $51.9 \mathrm{q}$ & $3.94(3 \mathrm{H}, \mathrm{s})$ & $51.9 \mathrm{q}$ \\
\hline 7-OH & $11.65(1 \mathrm{H}, \mathrm{s})$ & & $11.66(1 \mathrm{H}, \mathrm{s})$ & \\
\hline $10-\mathrm{OH}$ & $5.32(1 \mathrm{H}, \mathrm{s})$ & & & \\
\hline $11-\mathrm{OCH}_{3}$ & $3.91(3 \mathrm{H}, \mathrm{s})$ & $56.3 \mathrm{q}$ & & \\
\hline
\end{tabular}

aBy DEPT sequence.

$\left(3447 \mathrm{~cm}^{-1}\right)$ and conjugated carbonyl $\left(1656 \mathrm{~cm}^{-1}\right)$ groups. Its molecular formula was established as $\mathrm{C}_{17} \mathrm{H}_{18} \mathrm{O}_{6}$ on the basis of HRESIMS, which gave a quasi-molecular ion at $m / z 341.1009[\mathrm{M}+\mathrm{Na}]^{+} .{ }^{1} \mathrm{H}$ NMR spectrum of 1 exhibited two methyl singlets at $\delta_{\mathrm{H}} 2.28, \delta_{\mathrm{H}} 2.50$, four aromatic protons at $\delta_{\mathrm{H}} 6.27, \delta_{\mathrm{H}} 6.42, \delta_{\mathrm{H}} 6.50$ and $\delta_{\mathrm{H}} 6.58$, two methoxy groups at $\delta_{\mathrm{H}} 3.91$ and $\delta_{\mathrm{H}} 3.93$, in addition to two hydroxyl signals at $\delta_{\mathrm{H}} 5.32$ and $\delta_{\mathrm{H}} 11.65$. Its ${ }^{13} \mathrm{C}$ NMR spectrum displayed 17 carbon resonances, including an ester carbonyl carbon, four $s p^{2}$ methines, eight $s p^{2}$ quaternary carbons, two methyls and two methoxy carbons. The detailed analysis of the ${ }^{1} \mathrm{H}$ NMR and ${ }^{13} \mathrm{C}$ NMR data (Table 1) of 1 indicated that it had two benzene rings. The full structure of 1 was established by the correlated signals in the HMBC spectrum. A methocarbonyl group was confirmed by the long-range coupling from the methoxy signal at $\delta_{\mathrm{H}} 3.93$ to $\delta_{\mathrm{C}} 172.1$ (Figure 2). The downfield proton signal of a hydroxyl at $\delta_{\mathrm{H}} 11.65(7-\mathrm{OH})$ showed

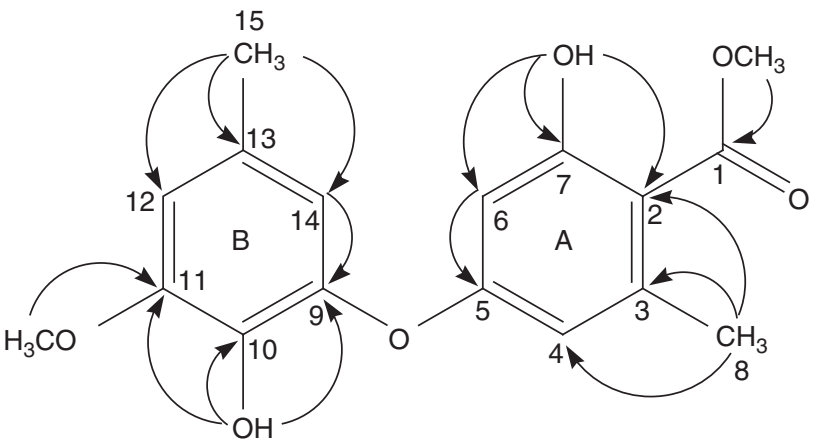

Figure 2 Key HMBC correlations of 1.

the $\mathrm{OH}$ group was in ortho position to the methocarbonyl. In addition to an oxygen atom attachment to C-5 revealed by the ${ }^{13} \mathrm{C}$ chemical shift of C-5 $\left(\delta_{\mathrm{C}} 162.5\right)$, the substituents of tetra-substituted ring $\mathrm{A}$ were assigned by the $\mathrm{HMBC}$ correlations from $\mathrm{H}_{3}-8$ to $\mathrm{C}-2, \mathrm{C}-$ 3, C-4, from $\delta_{\mathrm{H}} 11.65$ to C-2, C-6, C-7 and from H-6 to C-5. The observed crossing peaks in $\mathrm{HMBC}$ spectrum of 1 between $\delta_{\mathrm{H}} 3.91$ and $\mathrm{C}-11, \delta_{\mathrm{H}} 5.32(10-\mathrm{OH})$ and $\mathrm{C}-9, \mathrm{C}-10, \mathrm{C}-11, \mathrm{H}_{3}-15$ and $\mathrm{C}-12, \mathrm{C}-13$, $\mathrm{C}-14, \mathrm{H}-12$ and $\mathrm{C}-11, \mathrm{H}-14$ and $\mathrm{C}-9$ demonstrated the presence of another tetra-substituted benzene ring and established the substituents of ring $\mathrm{B}$ as shown in Figure 2. The ether linkage of the two benzene rings through $\mathrm{C}-4$ and $\mathrm{C}-9$ was confirmed by the molecular formula of $\mathrm{C}_{17} \mathrm{H}_{18} \mathrm{O}_{6}$. Furthermore, the ${ }^{1} \mathrm{H}$ and ${ }^{13} \mathrm{C}$ NMR data of 1 were very similar to those of gerfelin, ${ }^{8}$ except the two methoxy groups in 1 . This finalized the study and assigned the structure of 1 as methyl 2-hydroxy4-(2-hydroxy-3-methoxy-5-methylphenoxy)-6-methylbenzoate.

Compound 2 was also isolated as colorless oil with UV (EtOH) $\lambda_{\max } \mathrm{nm}(\log \varepsilon): 217$ (4.50), 264 (4.12), 302 (3.72). The IR spectrum of 2 showed the presence of hydroxyl $\left(3447 \mathrm{~cm}^{-1}\right)$ and conjugated carbonyl $\left(1655 \mathrm{~cm}^{-1}\right)$ groups. The ${ }^{1} \mathrm{H}$ NMR spectrum of 2 indicated five aromatic protons, two aromatic methyls, a downfield $\mathrm{OH}$ signal and a methoxy group. In the ${ }^{13} \mathrm{C}$ NMR spectrum of 2 , there were 12 $s p^{2}$ carbons in addition to three methyl carbons (one oxygenated one) and one carbonyl. These suggested the presence of two benzene rings in 2. Comparison of the NMR data (Table 1) of 2 with those of cordyol $\mathrm{B},{ }^{9}$ showed that compound 2 was identical to the aglycone of cordyol B and elucidated the structure of 2 as methyl 2-hydroxy-4(3-hydroxy-5-methylphenoxy)-6-methylbenzoate.

We examined the inhibitory activity of compounds $\mathbf{1}$ and $\mathbf{2}$ against the growth of human lung adenocarcinoma cell line A549 using the CCK-8 colorimetric method as described in our preceding paper. ${ }^{10}$ The result showed that compounds 1 and 2 inhibited the growth of A549 cells dose-dependently with an $\mathrm{IC}_{50}$ value of 5.3 and $15.2 \mu \mathrm{g} \mathrm{ml}^{-1}$, respectively.

\section{ACKNOWLEDGEMENTS}

This work was supported by the National Key Project for Basic Research (No. 2010CB126102) and the National Natural Science Foundation of China (No. 30771427 and 31000884).

1 Schwartsmann, G. et al. Anticancer drug discovery and development throughout the world. J. Clin. Oncol. 20, 47s-59s (2002).

2 Newman, D. J. \& Cragg, G. M. Microbial antitumor drugs: natural products of microbial origin as anticancer agents. Curr. Opin. Investig. Drugs. 10, 1280-1296 (2009). 
$3 \mathrm{Ma}, \mathrm{X}$. \& Wang, Z. Anticancer drug discovery in the future: an evolutionary perspective. Drug. Discov. Today. 14, 1136-1142 (2009).

4 Coseri, S. Natural products and their analogues as efficient anticancer drugs. Mini. Rev. Med. Chem. 9, 560-571 (2009).

5 Demain, A. L. \& Sanchez, S. Microbial drug discovery: 80 years of progress. J. Antibiot. 62, 5-16 (2009).

6 Flores-Bustamante, Z. R., Rivera-Orduña, F. N., Martínez-Cárdenas, A. \& Flores-Cotera, L. B. Microbial paclitaxel: advances and perspectives. J. Antibiot. 63, 460-467 (2010).
7 Emi, M., Youji, N., Yuzuru, I. \& Masayuki, H. A new enrichment method for the selective isolation of Streptomycetes from the root surfaces of herbaceous plants. Actinomycetologica. 21, 66-69 (2007).

8 Zenitani, S. et al. Gerfelin, a novel inhibitor of geranylgeranyl diphosphate synthase from Beauveria feline QN 22047 II structural elucidation. J. Antibiot. 56, 658-660 (2003).

9 Taridaporn, B., Seangaroon, Y., Kamolphan, I. \& Kanokarn, K. New diphenyl ethers from the insect pathogenic fungus Cordycep sp. BCC 186. Chem. Pharm. Bull. 55, 304-307 (2007).

10 Wang, J. D. et al. HSO71, A new furan-type cytotoxic metabolite from Streptomyces $s p$. HS-HY-071. J. Antibiot. 61, 623-626 (2008). 